\title{
The modulating effects of brain stimulation on emotion regulation and decision- making
}

\author{
Kyung Mook Choi ${ }^{*}$, David T. Scott and Seung-Lark Lim*
}

\author{
* Correspondence: \\ choikyun@umkc.edu; limse@umkc.edu \\ Department of Psychology, \\ University of Missouri-Kansas City, \\ 5030 Cherry Street, Kansas City, MO \\ 64110, USA
}

\begin{abstract}
Background: It has been reported that brain stimulation such as repetitive transcranial magnetic stimulation (rTMS) and transcranial direct current stimulation (tDCS) can modulate a variety of cognitions and emotions in humans. rTMS and tDCS studies provide strong possibilities of applications in the manipulation of emotion regulation and decision-making in humans.

Methods: We searched the literature by using keywords "rTMS," "tDCS," "emotion regulation," and "decision-making" on PubMed (http://www.ncbi.nlm.nih.gov/pubmed). Based on the search results, we reviewed studies on emotion regulation and decision-making using rTMS and tDCS modulations.

Results: Regarding emotion regulation, rTMS can influence both attentional and affective aspects of emotion regulation. tDCS studies for emotion regulation included diverse topics such as physiological arousal, social exclusion, mathematics anxiety, emotional reactions to pain stimuli, negative affect, momentary ruminative self-referent thoughts, and autonomic reactions to affective pictures. Decision-making studies have reported rTMS effects related to emotion such as delay-discounting tasks, food choice, and moral judgment. These studies have also investigated cognitive functions such as visuospatial attention, perception, object identification, spatial-working memory, visuomotor skills, task, and blameworthiness and punishment decisions. In tDCS studies for decision-making, it has increasingly been reported that tDCS influences moral judgment, risk-taking behaviors, choice modulation, delay discounting, maladaptive and perceptual decision-making, probabilistic guessing, perception of space and time, dual-task performance, model-based learning, addiction, food craving, sunk-cost effect, exploration-exploitation trade-offs and cognitive impulse control.
\end{abstract}

Conclusion: rTMS and tDCS have been shown to modulate behaviors relevant to emotion regulation and decision-making. The results of these numerous studies can be applied to clinical populations, and demonstrate that rTMS and tDCS may have many beneficial implications to those who have emotion regulation deficiencies.

Keywords: rTMS, tDCS, Emotion regulation, Decision-making, Neuromodulation

\section{Biomed Central}

(c) 2016 The Author(s). Open Access This article is distributed under the terms of the Creative Commons Attribution 4.0 International License (http://creativecommons.org/licenses/by/4.0/), which permits unrestricted use, distribution, and reproduction in any medium, provided you give appropriate credit to the original author(s) and the source, provide a link to the Creative Commons license, and indicate if changes were made. The Creative Commons Public Domain Dedication waiver (http://creativecommons.org/ publicdomain/zero/1.0/) applies to the data made available in this article, unless otherwise stated. 


\section{Background}

Emotion regulation and decision-making play an important role in human behaviors relevant to adaptation and problem solving. Cognition is related to processes including attention, memory, language, and problem-solving; whereas emotion has various characteristics such as states caused by rewards and punishments, conscious or unconscious evaluations of events, and basic affects such as fear and anger, according to past researchers [43]. Cognition and emotion are essential to emotion regulation and decision-making in various aspects and dimensions. According to Ochsner's recent model [53], generation, self-report, perception, and regulation of emotions are based on the interactions between cognition and emotion. However, emotion regulation is different from others in that it has up-and-downregulatory effects of emotion [53]. Decision-making consists of processes of encoding preferences, selecting and executing actions, and evaluating outcomes. These processes can be divided into input, process, output, and feedback [16].

Both emotion regulation and decision-making influence human behavior by top-down or bottom-up processing in the brain [44]. According to the interactive influence model of emotion and cognition, cognition interacts with emotion in both decision-making and emotion regulation. For example, decision-making is influenced by bottom-up processing such as increasing emotional reaction and decreasing cognitive capacity; it is further influenced by top-down processing such as regulating emotional responses by cognitive strategy [44]. Regarding the functional anatomy of the brain, emotion regulation and decisionmaking share dorsomedial, dorsolateral, ventrolateral, and medial regions of the prefrontal cortex [48]. Due to the anatomical characteristics of emotion regulation and decisionmaking, brain stimulation to these areas using rTMS and tDCS can influence emotion regulation and decision-making by modulating the interaction in the brain circuits.

Recently, it has been reported that brain stimulation such as repetitive transcranial magnetic stimulation (rTMS) and transcranial direct current stimulation (tDCS) can modulate a variety of cognitions and emotions in humans through experimental and clinical perspectives [32]. Past rTMS and tDCS studies have reported strong potentials for applying these different brain stimulations as a way to manipulate emotion regulation and decision-making in humans.

In this paper, we review the application of rTMS and tDCS on human emotion regulation and decision-making in experimental studies published thus far, as well as suggest future directions for tDCS and rTMS in emotion regulation and decision-making.

\section{Review}

Methods

We searched the literature by keywords "rTMS," "tDCS," "emotion regulation," and "decision-making" on PubMed (http://www.ncbi.nlm.nih.gov/pubmed). We reviewed studies on emotion regulation and decision-making using rTMS and tDCS modulations. In addition, we suggested clinical applications of rTMS and tDCS relevant to emotion and cognition for future studies. We collected papers that were published no later than December 2015.

\section{Neuronal mechanisms of rTMS and tDCS}

The effects of TMS are largely divided into two kinds based on the methods of stimuli applied. First, single- and paired-pulse TMS induce neurons to depolarize and discharge 
an action potential. These phenomena can be identified through changes in motorevoked potentials on electromyography of the primary motor cortex or phosphenes in the occipital cortex when TMS is applied [54]. Second, rTMS applied to the cortex through repeated stimuli causes relatively long-term effects beyond the duration of stimuli. rTMS increases or decreases excitability of the corticospinal tract according to the intensity of stimuli, the direction of the coil, and the frequency used [65, 73]. High frequency (HF) (5-20 Hz) rTMS increases cortical response, which is identified by a reduced motor-evoked potential threshold $[2,55]$. Low frequency (LF) $(\leq 1 \mathrm{~Hz})$ rTMS inhibits the cortical response [11] (Fig. 1). Recently, some studies demonstrated that the HF and LF rTMS induce neuronal plasticity [14, 40, 45, 74, 85, 86].

tDCS is based on the principle that the anode (positively-charged electrode) enhances cortical excitability, whereas the cathode (negatively-charged electrode) reduces it (Fig. 1). Anodal tDCS increases the neuronal excitability and cathodal tDCS decreases the neuronal excitability [50, 51]. A tDCS-positron emission tomograph (PET) study for the primary motor hand area showed that anodal tDCS increased regional cerebral blood flow in many cortical and subcortical regions compared to cathodal tDCS, while cathodal tDCS increased only the left dorsal premotor cortex [38]. tDCS's excitatory effect maintains up to $90 \mathrm{~min}$ [50]; however, daily repetitive tDCS has been shown to cause prolonged effects [1]. tDCS delivers a constant, weak, direct current to the region of the brain which is being stimulated. The efficacy of tDCS depends on current density and stimulation duration, which determine the induced electrical field strength and the occurrence and duration of after-effects, respectively [49]. Direct currents have generally been delivered via a pair of sponge electrodes moistened with tap water or sodium chloride $(\mathrm{NaCl})$ solution (size between 25 and $35 \mathrm{~cm}^{2}$ ), and the current density delivered has varied between 0.029 and $0.08 \mathrm{~mA} / \mathrm{cm}^{2}$ [49].

\section{rTMS and tDCS in emotion regulation and decision-making Emotion regulation \\ rTMS}

Recently, rTMS has been applied to emotion regulation, albeit studies are few thus far (Table 1). Vanderhasselt et al. [75] measured attentional processing of threatening information by HF rTMS over the right dorsolateral prefrontal cortex (DLPFC), using an emotional modification of the exogenous cueing task [58]. Individuals who scored higher on self-reports of state anxiety during baseline were more attentionally biased toward negative information after HF rTMS. In addition, state anxiety prior to stimulation correlated positively with induced attentional bias. Another study [15] investigated the effects of HF rTMS over the right or left DLPFC on the attentional processing of

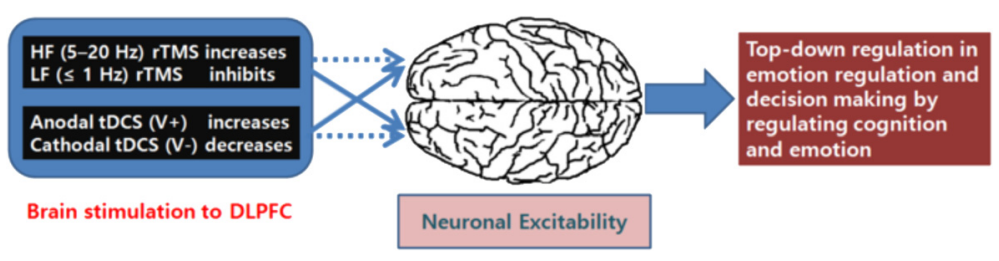

Fig. 1 rTMS and tDCS in emotion regulation and decision making 
Table 1 rTMS and tDCS studies in emotion regulation

\begin{tabular}{|c|c|c|c|c|}
\hline Authors & Target of study & Subjects/Design & Region stimulated/Frequency (rTMS)/Intensity/Duration & Results \\
\hline \multicolumn{5}{|l|}{ rTMS } \\
\hline Berger et al. 2015 [3] & $\begin{array}{l}\text { Autonomic reactions to } \\
\text { affective pictures }\end{array}$ & $\begin{array}{l}\text { F40/Crossover design (with an interval } \\
\text { of } 2 \text { weeks once with a real rTMS } \\
\text { and once with a sham rTMS) }\end{array}$ & $\begin{array}{l}\text { R DLPFC/one session of LF rTMS ( } 1 \mathrm{~Hz} \text { ) or } \\
\text { one session of } \mathrm{HF} \text { rTMS ( } 10 \mathrm{~Hz}) \text {, and sham } \\
\text { stimulation/10 Hz rTMS impulse train lasted } \\
5 \mathrm{~s} \text {, with an inter stimulus-interval of } 10 \mathrm{~s} \text {, } \\
\text { and included } 18 \text { trains with } 900 \text { pulses in } \\
\text { total, and had an overall duration of } 4.5 \text { min. } \\
\text { The } 1 \mathrm{~Hz} \text { rTMS was applied continuously for } \\
15 \text { min with } 900 \text { pulses in total. }\end{array}$ & $\begin{array}{l}\text { The LF rTMS increased heart rate } \\
\text { deceleration for negative and } \\
\text { neutral pictures, compared to } \\
\text { positive pictures. However, the } \\
\text { HF rTMS did not influence the } \\
\text { cardiac orienting response to } \\
\text { picture valence and arousal. }\end{array}$ \\
\hline De Raedt et al. 2010 [15] & $\begin{array}{l}\text { Attentional aspect of } \\
\text { emotion regulation }\end{array}$ & $\begin{array}{l}\text { F18 + F19/Combination of single-blind } \\
\text { randomized crossover within-subjects } \\
\text { design (HF-rTMS }- \text { L DLPFC and sham } \\
\text { stimulation }(n=18) \text {, one week's time } \\
\text { interval)) and between-subjects design } \\
\text { (HF-rTMS - R DLPFC ( } n=19) \text {, compared } \\
\text { to the sham condition of HF-rTMS - } \\
\text { L DLPFC) }\end{array}$ & $\begin{array}{l}\text { R or L DLPFC/HF ( } 10 \mathrm{~Hz}) \text { rTMS and sham/ } \\
\text { Stimulation intensity of } 110 \% \text { of the subject's } \\
\text { motor threshold/40 trains of } 3.9 \mathrm{~s} \text { duration, } \\
\text { separated by an intertrain interval of } 26.1 \mathrm{~s} \\
\text { (1560 pulses per session). }\end{array}$ & $\begin{array}{l}\text { R prefrontal HF rTMS delayed } \\
\text { disengagement from angry faces. }\end{array}$ \\
\hline Schutter and van Honk, 2009 [68] & $\begin{array}{l}\text { Mood in emotion } \\
\text { regulation }\end{array}$ & $\begin{array}{l}\text { F12/Single-blind, sham and occipital- } \\
\text { controlled crossover design, }\end{array}$ & $\begin{array}{l}\text { Cerebellar, occipital, or sham stimulation } \\
\text { (on three separate days)/LF ( } 1 \mathrm{~Hz} \text { ) rTMS/ } \\
\text { Stimulation intensity: } 45 \% \text { of maximum } \\
\text { machine output/for } 20 \mathrm{~min}\end{array}$ & $\begin{array}{l}\text { Cerebellar rTMS increased negative } \\
\text { mood after an emotion regulation } \\
\text { task for aversive and neutral scenes. }\end{array}$ \\
\hline Vanderhasselt et al. 2011 [75] & $\begin{array}{l}\text { Attentional aspect } \\
\text { of emotion regulation }\end{array}$ & $\begin{array}{l}\text { F28/Sham (placebo-)controlled, } \\
\text { double blind crossover design }\end{array}$ & $\begin{array}{l}\text { R DLPFC/HF }(10 \mathrm{~Hz}) \text { rTMS and sham/Stimulation } \\
\text { intensity: } 110 \% \text { of the motor threshold (MT). } \\
40 \text { trains of } 3.9 \mathrm{~s} \text { duration, separated by an } \\
\text { intertrain interval of } 26.1 \mathrm{~s}(1560 \text { pulses per } \\
\text { session). The total stimulation time was } \\
\text { approximately } 20 \text { min. }\end{array}$ & $\begin{array}{l}\text { Higher baseline self reported state } \\
\text { anxiety scores showed greater } \\
\text { attentional biased toward negative } \\
\text { information after HF rTMS. }\end{array}$ \\
\hline Zwanzger et al. 2014 [87] & $\begin{array}{l}\text { Affective processing of } \\
\text { emotional stimuli }\end{array}$ & $\begin{array}{l}40 \text { (F23)/Sham-controlled, between- } \\
\text { subject design }\end{array}$ & $\begin{array}{l}\text { R DLPFC/LF }(1 \mathrm{~Hz}) \text { rTMS and sham/Stimulation } \\
\text { intensity of } 120 \% \text { related to the individual } \\
\text { motor threshold/for } 30 \mathrm{~min}\end{array}$ & $\begin{array}{l}\text { Increased activation for fearful faces } \\
\text { compared to neutral faces in the } \\
\text { right temporal parietal junction } \\
\text { (TPJ) region between } 110 \text { and } 170 \mathrm{~ms} \text {. }\end{array}$ \\
\hline
\end{tabular}


Table 1 rTMS and tDCS studies in emotion regulation (Continued)

\section{tDCS}

Feeser et al, 2014 [20]

Arousal during

emotion regulation

48 (F25)/Double-blind, between-

subjects design

Peña-Gómez et al. 2011 [56]

Negative affect for

negative stimuli

Negative affect for negative pictures

Pain stimuli

Rêgo et al. 2015 [62]

Riva et al. 2015a [63]

Riva et al. 2015b [64]

Sarkar A, et al. 2014 [67]
Regulation of

negative emotions

(social exclusion)

Regulation of negative

$82(F 50)-\operatorname{Exp} 1 \& 40(F 25)-$ Exp2/

emotions (social exclusion) Double-blind, between-subjects design

Mathematics anxiety

80 (F63)/Between-subjects design
F16/Randomized, sham-controlled, crossover trial

17 smokers (F11)/Within-subjects design

24 (M12)/Double-blinded, randomized sham-controlled study.

Anodal tDCS or sham stimulation - rVLPFC, reference (cathodal) electrode - contralateral supraorbital area. $1.5 \mathrm{~mA}$ for $20 \mathrm{~min}$

Exp1: Cathodal tDCS (rVLPFC) or sham, reference (anodal) electrode - contralateral supraorbital area. Exp2: Cathodal tDCS (R posterior parietal cortex). reference (anodal) electrode - contralateral supraorbital area. $1.5 \mathrm{~mA}$ for $20 \mathrm{~min}$

DLPFC/L anodal/R cathodal tDCS and sham stimulation/1 mA for $30 \mathrm{~min}$
During down regulation decreased skin conductance responses (SCR) and emotional arousal ratings. During up regulation increased arousal ratings and SCR

Decreased negative affect for negative stimuli,while higher introversion personality dimension scores produced an increased effect

$R$ anodal tDCS - DLPFC decreased negative affect for negative pictures

L cathodal/R anodal, tDCS decreased valence and arousal evaluations compared to other tDCS conditions. Both left-cathodal/right-anodal and left-anodal/right-cathodal tDCS decreased self-pain perception, hostility and sadness compared to sham condition

Reduced behavioral aggression

Cathodal tDCS of rVLPFC increased negative emotional reactions brought out by social exclusion

Compared to sham stimulation high mathematics-anxiety individuals showed reduced RT on simple arithmetic decisions and cortisol concentrations; 
Table 1 rTMS and tDCS studies in emotion regulation (Continued)

however, compared to sham

stimulation, low math anxiety

subjects showed decreased RT

and cortisol concentration.

Vanderhasselt et al. 2013 [76] $\quad \begin{aligned} & \text { Momentary ruminative } \\ & \text { self-referent thoughts }\end{aligned}$

32 (F20)/Sham controlled within subjects DLPFC/L anodal (F3)/R cathodal (supra orbital

study. An interval of at least $48 \mathrm{~h}$.

area) and sham tDCS/2 mA for $20 \mathrm{~min}$

Reduced momentary ruminative

self-referent thoughts were reported

from subjects updating and shifting

from angry faces to neutral faces

$R$ right, $L$ left, $M$ male, $F$ female 
emotional information using an emotional modification of the exogenous cueing task during fMRI. Right prefrontal HF rTMS delayed disengagement from angry faces, decreased activation of the right DLPFC, dorsal anterior cingulate cortex (dACC) and left superior parietal gyrus; and increased activation of the right amygdala. Left prefrontal HF rTMS, on the other hand, diminished attentional engagement of angry faces and was associated with increased activity within the right DLPFC, dACC, right superior parietal gyrus and left orbitofrontal cortex. This demonstrates that HF rTMS modulates aspects of attention and related brain activations differently according to the regions of the frontal cortex stimulated.

LF (inhibitory) rTMS applied to the right DLPFC was reported to modulate early affective processing [87]. The study measured MEG activation for fearful and neutral faces as well as gender discrimination before and after rTMS. Results showed increased activation for fearful faces compared to neutral faces in the right temporal parietal junction (TPJ) region between 110 and $170 \mathrm{~ms}$. Berger et al. [3] studied autonomic reactions to affective pictures using LF rTMS $(1 \mathrm{~Hz})$ or HF rTMS $(10 \mathrm{~Hz})$ over the right DLPFC, compared to a sham stimulation. The LF rTMS increased heart rate deceleration for negative and neutral pictures compared to positive pictures. However, the HF rTMS did not influence the cardiac orienting response to picture valence and arousal. Schutter and van Honk [68] studied cerebellar function related to emotion regulation using LF rTMS. They demonstrated that LF rTMS to the cerebellum increased negative mood after an emotion regulation task for aversive and neutral scenes, indicating the importance of the cerebellum in emotion regulation. This demonstrates that LF rTMS to the DLFPC or cerebellum modulates emotion regulation related to affective processing.

In summary, rTMS can influence attentional aspects of emotion regulation $[15,75]$, affective processing of emotional stimuli [87], and autonomic reactions to affective pictures [3]. Also, these studies show that rTMS applied to the cerebellum can affect mood in emotion regulation [68].

$t D C S$

tDCS also has been applied to emotion regulation (Table 1). According to a study of tDCS's effects on the cognitive regulation of negative emotions using reappraisal instructions [52], anodal tDCS of the right DLPFC (F4 of the 10-20 international system) with cathode over the left supraorbital region during down regulation decreased skin conductance responses (SCR) and emotional arousal ratings when compared to a sham stimulation. However, anodal tDCS of the same region during up regulation increased arousal ratings and SCR [20]. These results reflect that the sympathetic nervous systems involved in arousal is modulated by stimulating the DLPFC. In addition, negative emotional reactions to social exclusion are related to right ventrolateral prefrontal cortex (rVLPFC). According to the literature, only two social exclusion studies using tDCS have been performed. The first study either socially excluded, or included, participants during anodal tDCS or sham stimulation, which was applied to the rVLPFC. After receiving stimulation, participants were given an opportunity to take out their aggression. The excluded participants who received anodal tDCS over the rVLPFC demonstrated reduced behavioral aggression compared to the sham stimulation condition, as well as equal levels of aggressive behaviors as those participants in the included condition [63]., The same research group conducted a second study on social exclusion using 
tDCS. Their findings showed that cathodal tDCS over the rVLPFC increased negative emotional reactions brought on by social exclusion, confirming that rVLPFC plays an important role in regulating negative emotions [64].

In a study on mathematics anxiety in healthy subjects using tDCS and salivary cortisol, Sarkar et al. [67] expected that anodal stimulation to the left DLPFC and inhibitory cathodal stimulation to the right DLPFC would produce the greatest reduction in negative emotional reactions. The authors based this on previous studies related to salivary cortisol [8] and positive and negative emotional processing of the left and right DLPFC $([31,78]$. Their results showed that real tDCS applied to the DLPFC reduced reaction time (RT) on simple arithmetic decisions and cortisol concentrations compared to sham stimulation in high mathematics-anxiety individuals. However, this stimulation did not decrease RT and cortisol concentration compared with sham stimulation in low mathematics-anxiety individuals.

Rêgo et al. [62] assessed emotional reactions to pain stimuli before and after tDCS to the DLPFC and compared the effects of left anodal/right cathodal, left cathodal/right anodal, and sham conditions. Left cathodal/right anodal tDCS decreased valence and arousal evaluations when compared to the other tDCS conditions. The results of this study also showed that both left cathodal/right anodal and left anodal/right cathodal tDCS decreased the perception of pain in participants, as well as decreased hostility and sadness when compared to the sham condition; however, there were no significant differences between the active tDCS conditions. Thus, these results suggest that stimulating the DLPFC modulates valence, arousal, and perception of pain stimuli.

A tDCS study of smokers showed that anodal tDCS over the right DLPFC decreased negative affect for negative pictures when compared to a sham condition, and left anodal stimulation when appraising smoking cues related to cigarettes, neutral, negative, and positive pictures [59]. In a study using anodal tDCS over the left DLPFC, researchers showed that participants decreased their negative affect for negative stimuli. This effect was higher in subjects who reported higher scores on the introversion personality dimension [56]. Vanderhasselt et al. [76] found that anodal tDCS of the left DLPFC did not directly influence momentary ruminative self-referent thoughts, but that the effects of tDCS were mediated indirectly by emotional working memory for angry faces. The researchers concluded that subjects who were better at shifting from angry faces to neutral faces reported less momentary ruminative self-referent thoughts after tDCS. Therefore, negative affect for negative stimuli as well as ruminative thoughts are modulated by tDCS to the DLPFC, indicating that brain stimulation may regulate emotion.

In summary, tDCS studies for emotion regulation investigated thus far are more diverse than rTMS studies. These studies show that, depending on the stimulated brain regions, anodal tDCS influences arousal during emotion regulation [20], regulation of negative emotions in situations characterized by social exclusion [63, 64], mathematics anxiety [67], emotional reactions to pain stimuli [62], negative affect for negative pictures [59], negative affect for negative stimuli [56], and momentary ruminative self-referent thoughts [76].

\section{Decision-making}

rTMS

rTMS studies have been published which investigate decision-making in relation to emotion (Table 2). Responses to rewards can be modulated by stimulating the medial 
Table 2 rTMS and tDCS studies in decision making

\begin{tabular}{|c|c|c|c|c|}
\hline Authors & Target of study & Subjects/Design & Region stimulated/Frequency (rTMS)/Intensity/Duration & Results \\
\hline \multicolumn{5}{|l|}{ rTMS } \\
\hline $\begin{array}{l}\text { Buckholtz et al. } \\
2015[9]\end{array}$ & $\begin{array}{l}\text { blameworthiness and } \\
\text { punishment decisions }\end{array}$ & $\begin{array}{l}66(\mathrm{M} 32) / 2 \times 2 \text { between-groups design, with rTMS } \\
\text { condition (active versus sham) and hemisphere } \\
\text { (left versus right DLPFC) as between-subject factors. }\end{array}$ & $\begin{array}{l}\mathrm{R} \text { or } \mathrm{L} \text { DLPFC } / 1 \mathrm{~Hz} \text { rTMS stimulation and sham. The } \\
\text { maximum stimulation duration in any one session } \\
\text { was approximately } 30 \mathrm{~min} \text {, constraining each of the } \\
\text { two rating sessions to } 15 \mathrm{~min} \text {. The two sessions } \\
\text { were separated by no less than } 48 \mathrm{hr} \text { and no more } \\
\text { than } 2 \text { weeks. }\end{array}$ & $\begin{array}{l}\text { LF rTMS over DLPFC lowerd punishment } \\
\text { for culpable acts, but did not } \\
\text { affect blameworthiness judgments. }\end{array}$ \\
\hline $\begin{array}{l}\text { Camus et al. } \\
2009[10]\end{array}$ & food choice & 56 (M30) - Exp1 \& 15 (M8) - Exp 2 & $\begin{array}{l}\text { R DLPFC/1 Hz-rTMS/Two control groups ( } 1 \mathrm{~Hz}-\mathrm{rTMS} \text { - } \\
\text { vertex and sham)/Stimulation intensity: } 50 \% \text { of the } \\
\text { stimulator maximum. A single, } 15 \mathrm{~min}, 1 \mathrm{~Hz} \text { rTMS } \\
\text { train ( } 900 \text { pulses). } 1 \mathrm{st} \text { control group ( } 15 \mathrm{~min}, 1 \mathrm{~Hz} \\
\text { rTMS train at } 50 \% \text { of the stimulator maximum). } 2 \mathrm{nd} \\
\text { control group - sham rTMS over the right DLPFC, }\end{array}$ & $\begin{array}{l}1 \mathrm{~Hz}-\text {-rTMS to the R DLPFC decreased } \\
\text { values assigned to food stimuli }\end{array}$ \\
\hline $\begin{array}{l}\text { Cho et al. } \\
2015 \text { [13] }\end{array}$ & delay discounting & 24 (F11)/Within-subject design & $\begin{array}{l}\text { MPFC and vertex stimulation (control condition)/ } 10 \\
\text { Hz-rTMS. Stimulus intensity: } 80 \% \text { of the active motor } \\
\text { threshold/Applied during the behavior study with } \\
\text { the delay discounting task }\end{array}$ & $\begin{array}{l}10 \mathrm{~Hz}-\mathrm{rTMS} \text { to the MPFC increased the } \\
\text { preference toward delayed larger-size } \\
\text { rewards and decreased the choices } \\
\text { for immediate small-size rewards. }\end{array}$ \\
\hline $\begin{array}{l}\text { Gongora et al. } \\
2016[25]\end{array}$ & $\begin{array}{l}\text { visuomotor task involving } \\
\text { decision making }\end{array}$ & $12(\mathrm{M} 4)$ & $\begin{array}{l}\text { Superior Parietal Cortex (SPC; Brodmann area 7)/1 Hz - } \\
15 \mathrm{~min}-80 \% \text { Resting Motor Threshold (15 min) }\end{array}$ & $\begin{array}{l}\text { Absolute beta power decreased in } \\
\text { Fp1 and increased in Fp2 at rest } \\
\text { before task, but Fp2's absolute } \\
\text { beta power increased during the } \\
\text { task, and F4's abolute beta power } \\
\text { decreased, and F7's abolute beta } \\
\text { power increased during the task } \\
\text { and decresed at rest after task. } \\
\text { The parietal regions (P3, Pz and } \\
\text { P4)'s abolute beta power decreased } \\
\text { during the visuomotor task, } \\
\text { compared to rest conditions. }\end{array}$ \\
\hline $\begin{array}{l}\text { Ishibashi et al. } \\
2011 \text { [33] }\end{array}$ & $\begin{array}{l}\text { function and manipulation } \\
\text { tool knowledge }\end{array}$ & $13(\mathrm{~F} 6)$ & $\begin{array}{l}\text { L lateral ATL and L IPL, occipital pole (control site)/ } \\
\text { Inhibitory rTMS/Stimulation was delivered at } 120 \% \text { of } \\
\text { motor threshold but kept at } 67 \% \text { of the device's } \\
\text { maximum output if it exceeded this criterion (This } \\
\text { occurred in } 16.7 \% \text { of the sessions). Average stimulation }\end{array}$ & $\begin{array}{l}\text { Inhibitory rTMS to } L \text { lateral ATL } \\
\text { increased RT for the "function" } \\
\text { judgments, whereas inhibitory } \\
\text { rTMS of L IPL increased RT for } \\
\text { the "manipulation" judgments. }\end{array}$ \\
\hline
\end{tabular}


Table 2 rTMS and tDCS studies in decision making (Continued)

intensity was 58.8\%. Participants received 10-min of TMS stimulation (1 Hz for $600 \mathrm{~s}$ ).

$\mathrm{R}$ posterior parietal cortex (PPC), R premotor cortex (SFG), and R DLPFC/HF rTMS $(25 \mathrm{~Hz}) /$ rTMS trains of eight stimuli at $25-\mathrm{Hz}$ frequency (mean stimulation time: $300 \mathrm{~ms}$ ) were delivered at an intensity of $110 \%$ of motor threshold

Philiastides et al. perception

2011 [57]

Sheffer et al.

$2013[69$

delay discounting

47 smokers \& 19 nonsmokers/Single-blind, within-subjects design

28 (M15)/Within-subject design (separated

by $6-8$ days)

Studer et

visuospatial attention

Tassy et al.
$2012[72]$

moral judgment

Viggiano et al.

$2008[77]$

tDCS

Bogdanov et al. Sunk-cost effect (Cost of 2015 [4] past expenses)
60 (F30)/Double-blind, sham-controlled,

between-subject design.
L DLPFC/LF rTMS and sham/Stimulation intensity: $110 \%$ of motor threshold/Two separate 12 min rTMS sessions: a $1 \mathrm{~Hz}$ LF rTMS to the L DLPFC and a $12 \mathrm{~min}$ sham rTMS over the same are

L DLPFC/Three sessions of HF rTMS $(20 \mathrm{~Hz}, 10 \mathrm{~Hz}$ sham)/900 pulses of HF rTMS $(20 \mathrm{~Hz}, 10 \mathrm{~Hz}$, sham) separated by at least 48 hours $-20 \mathrm{~Hz} \& 10 \mathrm{~Hz}(110 \%$ MT, 1 second on, 20 seconds off), sham $(10 \mathrm{~Hz}$, second on, 20 seconds off, $5.5 \mathrm{~mA}$ )

Inhibitory CTBS - AG bilaterally, CTBS - PMC bilaterally (active control condition) and without stimulation/ Consisting of bursts of three pulses at $50 \mathrm{~Hz}$ repeated at $5 \mathrm{~Hz}$ for $30 \mathrm{~s}$ (450 pulses) per hemisphere.

Stimulation intensity: $40 \%$ of maximum machine output.

R DLPFC/1 Hz-rTMS (a single, 15-min, 900 pulses) or sham/Stimulation intensity: $54 \%$ of the stimulator maximum output

No rTMS (baseline), real rTMS (L DLPFC), real rTMS (R DLPFC), and sham rTMS (L DLPFC)/10 Hz-rTMS/An intensity of $90 \%$ RMT of the contralateral FDI/6 pulses (train duration $500 \mathrm{~ms}$ )

R DLPFC (F4), a reference - CZ. Anodal, cathodal, or sham stimulation. A current of $1.075 \mu \mathrm{A}$, leading to a current
Both HF rTMS - R posterior parietal cortex (PPC) and R DLPFC increased RT during the delay phase (no effect observed for R SFG). HF rTMS $R$ DLPFC increased RT selectively during the decision phase

Decreased accuracy and increased RT

HF rTMS to the L DLPFC decreased discounting of monetary gains and increased discounting of monetary losses in both smokers and

nonsmokers, but had no effect on cigarette consumption in smokers

cTBS - AG affects decision-making tasks requiring visuospatial attention by disrupting the relationship between decision latencies and the probability of winning/losing.

$1 \mathrm{~Hz}-\mathrm{rTMS}$ to the R DLPFC increased utilitarian responses during objective evaluation of moral dilemmas,

rTMS of either $L$ or R DLPFC increased the RT for spatially filtered living stimuli, but not of non-filtered living stimuli or of non-living objects.

Anodal tDCS significantly increased a sunk-cost effect, but cathodal or 
Table 2 rTMS and tDCS studies in decision making (Continued)

25 marijuana users (M15)/Single-center, doubledblinded, randomized, and sham-controlled trial

12 smokers (M5)/Two five-day tDCS (active or sham) - A crossover, blind at four levels (group allocator, subjects, tDCS provider, outcome assessor), randomized, sham-controlled design (3 months separated the two tDCS regimens) sham stimulation. $2 \mathrm{~mA}$ for $30 \mathrm{~min}$ density of $0.043 \mathrm{~mA} / \mathrm{cm}^{2}$ for the electrode over the DLPFC and $0.011 \mathrm{~mA} / \mathrm{cm}^{2}$ for the reference electrode. The stimulation lasted for as long as the individual participant worked on the investment task but not longer than $30 \mathrm{~min}$.

DLPFC/R anodal/L cathodal tDCS, $L$ anodal/R cathodal tDCS, or sham stimulation. 2 mA. tDCS started 5 min before the task began and was delivered during the entire course of the risk task (10 min)

DLPFC/L anodal/R cathodal tDCS, $R$ anodal/L

cathodal tDCS, or sham stimulation. $2 \mathrm{~mA}$.

The tDCS started 5 min before the task began and was delivered during the entire course of the risk task (10 min)

DLPFC/left anodal/right cathodal, left cathodal/right anodal, or sham stimulation. $2 \mathrm{~mA}$, Stimulation began 5 minutes before onset of experimental tasks and 5 minutes before onset of experimental tasks
continued throughout completion of all tasks continued throughout
(within 19 minutes)

DLPFC/R anodal/L cathodal tDCS, $L$ anodal/R cathod tDCS, or sham stimulation. 2 mA. tDCS started 5 min before the task began and was delivered during the entire course of the risk task ( $<10 \mathrm{~min})$

DLPFC/R anodal/L cathodal tDCS, $L$ anodal/R cathod tDCS or sham stimulation. 2 mA. tDCS started 5 min before the task began and was delivered during the whole course of the BART ( $<15 \mathrm{~min}$ )

sham stimulation did not change it. Also, tDCS did not influence choices when there were no investments.

L anodal/R cathodal tDCS group caused more often high-risk prospects compared to sham or $\mathrm{R}$ anodal/L cathodal stimulation groups.

Both $L$ anodal/R cathodal tDCS of DLPFC and $R$ anodal/L cathodal tDCS showed more risky tendencies in marijuana users. In marijuana users, $R$ anodal/L cathodal tDCS decreased marijuana cravings.

Left cathodal/right anodal tDCS over DLPFC decreased risk-taking under a context of haste. The reduction of risk-taking was large in more impulsive individuals.

$R$ anodal/L cathodal tDCS caused the safe prospect more often, compared to $L$ anodal/R cathoda and sham stimulation

Groups receiving anodal tDCS over R or L DLPFC showed a risk-averse response.

DLPFC/Active tDCS (R anodal/L cathodal tDCS) and

Active tDCS decreased significantly the number of cigarettes smoked compared to sham stimulation and the effects maintained for 4 days. 
Table 2 rTMS and tDCS studies in decision making (Continued)

\begin{tabular}{|c|c|c|c|}
\hline $\begin{array}{l}\text { Filmer et al. } 2013 \\
\text { [22] }\end{array}$ & dual-task performance & $\begin{array}{l}18(\mathrm{M} 3) / \mathrm{tDCS} \text { during three testing sessions on } \\
\text { different days (The average time between } \\
\text { sessions: } 5 \text { days) }\end{array}$ & $\begin{array}{l}\text { L posterior lateral prefrontal cortex (pLPFC)/An } \\
(9 \mathrm{~min}), \text { cathodal }(9 \mathrm{~min}) \text {, or sham ( } 1 \mathrm{~min} 15 \mathrm{se} \\
\text { Reference electrode }-\mathrm{R} \text { supraorbital region/Cur } \\
\text { density: } 0.029 \mathrm{~mA} / \mathrm{cm} 2 \text { (current intensity }=0.7\end{array}$ \\
\hline $\begin{array}{l}\text { Fregni et al. } \\
2008[23]\end{array}$ & food craving & $\begin{array}{l}23 \text { (F21) - } 21 \text { completed the entire study } \\
\text { (3 different sessions of treatment) (at } 48 \text {-hour } \\
\text { intervals)/Placebo-tDCS-controlled, randomized, } \\
\text { double-blind, crossover study }\end{array}$ & $\begin{array}{l}\text { DLPFC/L anode/R cathode tDCS, } R \text { anode/L ca } \\
\text { tDCS, and sham tDCS. } 2 \text { mA for } 20 \text { min. }\end{array}$ \\
\hline $\begin{array}{l}\text { Gorini et al. } \\
2014 \text { [26] }\end{array}$ & addiction & $\begin{array}{l}18 \text { cocaine users (M10) \& } 18 \text { non-abusers/ } \\
\text { Single-blind, sham-controlled study }\end{array}$ & $\begin{array}{l}\text { DLPFC. } L \text { anodal/R cathodal tDCS, } R \text { anodal/L } \\
\text { cathodal tDCS, or sham stimulation (at least } \\
\text { 48-hour intervals). } 1.5 \mathrm{~mA} \text { for } 20 \text { min. }\end{array}$ \\
\hline
\end{tabular}

2014 [26] Single-blind, sham-controlled study

\section{Hecht et al. probabilistic guessing 28 (M14)}

2010 [29]

Hecht et al.

2013 [30]

Javadi et al

2015 [34]

perceptual decisionmaking delay discounting
DLPFC/R anodal/L cathodal group, $L$ anodal/R cathodal group, or control group (no stimulation). $2 \mathrm{~mA}$. tDCS started immediately before the prediction task began and was delivered during the whole course of the five-block experimen ( $22 \mathrm{~min}$ )

DLPFC/R anodal/L cathodal tDCS, $L$ anodal/R cathodal DLPFC tDCS, and sham stimulation $1.6 \mathrm{~mA}$ for $20 \mathrm{~min}$

14 (F7)/Within-subject design (a minimum 2 days ( $\sim 77 \mathrm{~h}$ ) interval between sessions)

$12(F 6)-\operatorname{Exp} 1 \& 45(F 26)-\operatorname{Exp} 2 / \operatorname{Exp} 1(n=12)$ only one stimulation condition (bilateral stimulation) \& Exp2 $(n=45)$ - three stimulation conditions (bilateral, anodal unilateral, and cathodal unilateral stimulations)

Primary motor cortex (PMC) (C3 and C4)/Bilateral tDCS ( $L$ anodal PMC/R cathodal PMC, R anodal PMC/L
Cathodal tDCS to $L$ pLPFC reduced RT for the multitask session.

Sham stimulation increased craving but anode L/cathode R tDCS did not increase craving (anode L/ cathode R can suppress food craving).

BART: both cocaine users and nonabusers decreased risky behavior after both active tDCS. GDT: cocaine users increased safe behavior after $R$ anodal stimulation and increased risk-taking behavior after $L$ anodal stimulation, whereas control subjects increased safe behavior by only $R$ anodal stimulation.

No difference in strategy between the three groups, but participants in the left anodal/right cathodal group decreased RT when choosing the most frequent alternative.

Anodal left/cathodal R DLPFC tDCS increased smaller immediate gains rather than larger-delayed options compared to sham stimulation. Anodal tDCS over the PMC increased responses using the contralateral hand; whereas, upper arm, R anodal PMC/L upper arm), Unilateral- $\quad$ cathodal tDCS over the PMC cathodal tDCS ( $L$ cathodal PMC/R upper arm, R cathodal increased responses using the $\mathrm{PMC} / \mathrm{L}$ upper arm)/1.5 mA for $10 \mathrm{~min}$ after the first ipsilateral hand. In all tDCS phase and continued for another 5 min during the conditions, RTs decreased when
response shifted toward left hand 
Table 2 rTMS and tDCS studies in decision making (Continued)

Mengarelli et al. choice modulation 48 (F28)

2015 [46]

Minati et al.

$2012[47]$

Ouellet et al.

2015 [42]

Pripfl et al.

2013 [60]

risk-taking behavior

decision-making and

cognitive impulse control
F 20 with frequent food cravings/A double-blind sham-controlled within-subjects crossoverdesign

20 with frequent food cravings/A double-blind sham-controlled within-subjects crossoverdesign

F47/Single-blind design

45 (F29)/A single-blind, three-arm, randomized and sham-controlled study.

8 smokers (F10) \& 18 non-smokers (F15)/Withinsubjects design (at least 1 week between sessions).
DLPFC/R anodal/L cathodal tDCS and sham tDCS. $2 \mathrm{~mA}$ for $20 \mathrm{~min}$.

Anodal, cathodal, and sham stimulation - L DLPFC (reference electrode: R parietal cortex (P4). 10 min of tDCS before starting with the moral judgment task with $2 \mathrm{~mA}$ and 5 seconds fade-in time. The stimulation
continued and participants rated the personal moral dilemmas. The maximum stimulation time did not exceed 20min

DLPFC, L cathodal tDCS, R cathodal tDCS (anode electrode - contralateral supraorbital area), or sham stimulation (over the same cortical areas, with the cathode electrode over the left and the right,

respectively). $1 \mathrm{~mA}$ for $15 \mathrm{~min}$

Three groups of female subjects ( $L$ anodal/R cathodal, $\mathrm{R}$ anodal/L cathodal, and sham tDCS)/DLPFC. $2 \mathrm{~mA}$. Stimulation was enabled approximately 3 min before starting the task and disabled immediately upon completion (about $20.5 \mathrm{~min}$ )

Orbitofrontal cortex (OFC)/L anodal left/R catrhodal, $R$ anodal left/L catrhodal, or sham/1.5 mA for $30 \mathrm{~min}$. Anodal and cathodal current densities of $0.04 \mathrm{~mA} / \mathrm{cm}$ 2 and $0.027 \mathrm{~mA} / \mathrm{cm} \mathrm{2}$, respectively.

DLPFC/R anodal/L cathodal tDCS, $L$ anodal/R cathoda DCS, and sham stimulation $0.45 \mathrm{~mA}$ (delivered over an electrode size of about $5 \mathrm{~cm}^{2}$ ) for $15 \mathrm{~min}$ and increased when response shifted away from the left hand.

Active tDCS decreased craving for sweet foods, but not savory foods Anodal stimulation - L DLPFC decreased individual appropriateness ratings and shifted toward nonutilitarian actions.

Cathodal tDCS - L DLPFC reduced choice-induced preference change.

$R$ anodal/L cathodal tDCS significantly increased response confidence, independently of accept/reject response

Anodal tDCS over orbitofrontal cortex (OFC) regardless of laterality increased advantageous decision-making and cognitive impulse control, compared to sham tDCS.

In both the smoking and nonsmoking groups, risk taking was decreased in the "cold" task after the anodal left tDCS, whereas the opposite effect was seen in the "hot" task after anodal right tDCS. 
Table 2 rTMS and tDCS studies in decision making (Continued)

\begin{tabular}{|c|c|c|c|c|}
\hline $\begin{array}{l}\text { Raja Beharelle } \\
\text { et al. } 2015 \text { [61] }\end{array}$ & $\begin{array}{l}\text { Exploration-exploitation } \\
\text { trade-offs }\end{array}$ & 79(F23)/Double-blind design & $\begin{array}{l}\text { R Frontopolar Cortex (MNI peak: } x=27, y=57, z= \\
\text { 6)/Anodal, cathodal, or sham tDCS } 1 \mathrm{~mA} \text {. The } \\
\text { stimulation } 3 \text { min before subjects started the } \\
\text { bandit task and continued throughout tasks }\end{array}$ & $\begin{array}{l}\text { Cathodal stimulation increased choices } \\
\text { of the highest rewards, but anodal } \\
\text { stimulation influenced choices less by } \\
\text { anticipated rewards, but rather by } \\
\text { recent negative reward prediction errors }\end{array}$ \\
\hline $\begin{array}{l}\text { Smittenaar et al. } \\
2014 \text { [70] }\end{array}$ & model-based learning & 22 (F11)/Within-subject, double-blind & $\begin{array}{l}\text { R DLPFC/Anodal tDCS (cathodal electrode over } \\
\text { the inion) and sham stimulation)/2 mA for } 25 \mathrm{~min} \text {. }\end{array}$ & $\begin{array}{l}\text { One stimuli was more strongly associated } \\
\text { with the originally selected stimuli than } \\
\text { the other. Active tDCS does not } \\
\text { significantly affect model-based or } \\
\text { model-free control during a } \\
\text { behavioral task. }\end{array}$ \\
\hline $\begin{array}{l}\text { Woods et al. } \\
2014[79]\end{array}$ & $\begin{array}{l}\text { perception of space } \\
\text { and time }\end{array}$ & $\begin{array}{l}16 \text { (F10)/Three sessions on separate days } \\
\text { (time range between sessions: } 6-8 \text { days). }\end{array}$ & $\begin{array}{l}\text { Frontal - } R \text { anodal (F4)/L cathodal (F3), parietal - } R \\
\text { anodal (CP4)/L cathodal (CP3) (1.5 mA for } 20 \text { min) } \\
\text { or sham stimulations (F3/F4 or CP3/CP4 - } \\
\text { counterbalanced across participants. }\end{array}$ & $\begin{array}{l}\text { Parietal stimulation affected perception } \\
\text { of spatial causality, while the frontal } \\
\text { stimulation affected perception of } \\
\text { both spatial and temporal causality. }\end{array}$ \\
\hline Xu et al. 2013 [80] & addiction & 24 smokers (F3)/Single-blind design & $\begin{array}{l}\text { Anode tDCS - L DLPFC/cathode tDCS - R supra-orbital } \\
\text { area ( } 2 \mathrm{~mA} \text { for } 20 \mathrm{~min} \text { ) and sham stimulation }\end{array}$ & $\begin{array}{l}\text { Anode tDCS - L DLPFC and cathode } \\
\text { tDCS - R supra-orbital area decreased } \\
\text { significantly negative affect. }\end{array}$ \\
\hline $\begin{array}{l}\text { Xue et al. } \\
2012 \text { [81] }\end{array}$ & $\begin{array}{l}\text { maladaptive decision- } \\
\text { making }\end{array}$ & $18(\mathrm{M} 9)$ & $\begin{array}{l}\text { LPFC (the intersection of the F3-T3 line and the F7- } \\
\text { C3 line)/Anodal tDCS - left lateral prefrontal cortex } \\
\text { Control condition - Visual cortex (VC), Reference } \\
\text { electrode - left cheek/1.5 mA for } 10 \text { min }\end{array}$ & $\begin{array}{l}\text { Anodal tDCS - left LPFC increased the } \\
\text { use of the gambler's fallacy strategy. }\end{array}$ \\
\hline $\begin{array}{l}\text { Ye et al. } \\
\text { 2015a [82], }\end{array}$ & risk-taking behavior & $60(F 36)$ & $\begin{array}{l}\text { DLPFC/R anodal/L cathodal tDCS, } L \text { anodal/R cathodal } \\
\text { tDCS or sham stimulation } / 2 \mathrm{~mA} \text { for } 15 \mathrm{~min}\end{array}$ & $\begin{array}{l}\text { Group receiving sham stimulation } \\
\text { showed more conservative and safe } \\
\text { options. Groups receiving either } R \\
\text { anodal/L cathodal tDCS or } L \text { anodal/ } \\
R \text { cathodal tDCS did not show } \\
\text { significant changes after tDCS. }\end{array}$ \\
\hline $\begin{array}{l}\text { Ye et al. } \\
2015 b[83]\end{array}$ & risk-taking behavior & $60(\mathrm{~F} 35)$ & $\begin{array}{l}\mathrm{R} \text { anodal } / \mathrm{L} \text { cathodal DLPFC, } \mathrm{L} \text { anodal/R cathodal } \\
\text { DLPFC, or sham stimulation } / 2 \mathrm{~mA} \text { for } 15 \mathrm{~min}+ \\
\text { another } 3 \text { min (second task) }\end{array}$ & $\begin{array}{l}\mathrm{R} \text { anodal } / \mathrm{L} \text { cathodal tDCS induced } \\
\text { more risky options in the gain frame } \\
\text { and more safe options in the loss frame. }\end{array}$ \\
\hline
\end{tabular}


prefrontal cortex (MPFC) or the DLPFC using rTMS. When young healthy subjects performed delay-discounting tasks after $10 \mathrm{~Hz}$-rTMS was applied to their MPFC or vertex stimulation (control condition), rTMS to the MPFC increased the preference toward delaying larger-sized rewards, while decreasing the choices for immediate smallsize rewards (Cho et al. [13]). In another study, Sheffer et al. [69] showed that three sessions of HF rTMS $(20 \mathrm{~Hz}, 10 \mathrm{~Hz}$, sham) over the left DLPFC decreased discounting of monetary gains and increased discounting of monetary losses in both smokers and nonsmokers, but had no effect on cigarette consumption in smokers. In Camus et al. [10] study, LF rTMS to the right DLPFC decreased values assigned to food stimuli. In their study, two control groups were added to the active rTMS group. The first control group received stimulation over the vertex, and the second control group received sham rTMS over the right DLPFC, using a placebo-stimulator. Compared to the two control groups, the group that received LF rTMS over the right DLPFC decreased their perceived values assigned to food stimuli. Because the MPFC has been reported to be related to reward encoding and outcome expectancies [48], HF rTMS to this region can shift reward decision-making from immediate to delayed rewards, which is implicated in goal-directed behaviors. HF rTMS to the left DLPFC can modulate monetary gains and losses; it has also been shown that LF rTMS to right DLPFC can decrease perceived values of food. These studies indicate that rTMS may be an effective tool for treating addiction.

When measuring rTMS's effects using the "dilemma" scenarios selected from a battery developed by Greene et al. [28], LF rTMS over the right DLPFC increased utilitarian responses during objective evaluation of moral dilemmas, compared to a sham group. For the results, the authors suggested that the right DLPFC stimulated by LF rTMS induced participants toward a rational cognitive control process, and integrated emotions caused by contextual information appraisal in moral judgments [72]. Buckholtz et al. [9] studied blameworthiness and punishment decisions using LF rTMS over the DLPFC. LF rTMS over DLPFC lowered punishment ratings for culpable acts, but did not affect blameworthiness judgments. Tassy et al. and Buckholtz et al.'s studies showed that rTMS can influence the judgement for moral problems.

On the other hand, rTMS can modulate cognitive functions. Inhibitory continuous theta burst stimulation (cTBS) to the angular gyrus (AG) affected decision-making tasks requiring visuospatial attention by disrupting the relationship between decision latencies and the probability of winning/losing [71]. In a study on the causal role of DLPFC in perceptual decision-making using a speeded perceptual categorization task (face-versus-car categorization task), LF rTMS applied to the left DLPFC decreased accuracy and increased RT compared to a sham condition [57]. In an object identification study using HF rTMS [77], when subjects performed object identification tasks consisting of spatially filtered living and non-living stimuli, HF rTMS of either the left or right DLPFC increased the RT for spatially filtered living stimuli, but not for non-filtered living stimuli or non-living objects. In a spatial working memory study [36], HF rTMS applied to both the right posterior parietal cortex (PPC) and the right DLPFC increased RT during the delay phase. The results showed that HF rTMS to the right DLPFC increased RT selectively during the decision phase, demonstrating the roles of the PPC and the DLPFC in the delay and decision phases related to spatial working memory. In a study on the lateral anterior temporal lobe (ATL) and the inferior parietal lobule 
(IPL) in coding function (what for) and manipulation (how) of tools [33], LF rTMS to lateral ATL increased RT for the "function" judgments, whereas LF rTMS of IPL increased RT for the "manipulation" judgments. Gongora et al. [25] conducted a visuomotor task using LF rTMS and quantitative electroencephalography. After LF rTMS, compared to pre-LF rTMS, absolute beta power decreased in the Fp1 electrode and increased in the Fp2 electrode at rest before the task. During the task, the Fp2 electrode's absolute beta power increased, F4 electrode's absolute beta power decreased, and F7 electrode's absolute beta power increased. After the task, at rest, F7 electrode's absolute beta power decreased. The parietal regions (P3, Pz and P4)'s absolute beta power decreased during the visuomotor task compared to the rest conditions. The results showed interferences in parieto-frontal network through the changes of the absolute beta power by LF rTMS. These rTMS studies relevant to cognitive functions suggest that human cognitive abilities can be improved by brain stimulation.

In summary, in decision-making studies related to emotion, rTMS modulates delayed discounting [13, 69], food choice [10], moral judgment [72], and blameworthiness and punishment decisions [9]. In decision-making studies relevant to cognitive functions, rTMS affects visuospatial attention [71], perception [57], object identification [77], spatial working memory [36], function and manipulation tool knowledge [33], and visuomotor tasks [25].

$t D C S$

Recently, tDCS has been extensively used in decision-making studies (Table 2). In studies on risk-taking aversion using tDCS, Ye et al. [82] demonstrated that tDCS to the DLPFC could prevent wealth effect. ${ }^{1}$ The group receiving sham stimulation showed more conservative and safer options. In contrast, groups receiving either right anodal/left cathodal or left anodal/right cathodal tDCS did not show significant changes after tDCS. The same research group [83] demonstrated that groups receiving the right anodal/left cathodal tDCS over DLPFC chose riskier options in the gain frame and safer options in the loss frame. These studies show that real tDCS to the DLPFC can reduce wealth effect and risk aversion, but the tendency differs depending on the gain and loss frame.

In Minati et al. [47]'s study, three groups (left anodal/right cathodal, right anodal/left cathodal, and sham tDCS to DLPFC) were compared while performing monetary gambles (potential win, loss, and outcome probability). The results showed that right anodal/left cathodal tDCS significantly increased response confidence, independently of accept/reject response, albeit tDCS did not affect task performance or risk propensity. tDCS also has shown different modulation effects in risk-taking behavior depending on age. For younger healthy subjects performing risk-taking tasks relevant to gambling, right anodal/left cathodal stimulation over the DLPFC caused the safe prospect to be chosen more frequently, compared to left anodal/right cathodal and sham stimulation [18]. In contrast, for older subjects (age: 50-85 years), left anodal/right cathodal stimulation caused high-risk prospects more often picked compared to sham or right anodal/left cathodal stimulation groups [5]. Cheng and Lee [12] studied risk-taking behavior using tDCS in young healthy subjects. Right anodal/left cathodal tDCS over DLPFC decreased risk-taking under a context of haste. The reduction of risk-taking was larger in more impulsive individuals.

When making a choice in a context of increasing risk, groups receiving anodal tDCS over the right or the left DLPFC (bilateral tDCS groups with cathodal tDCS to the 
contralateral region of DLPFC) showed a risk-averse response. These groups made fewer pumps on the Balloon Analog Risk Task (BART) [39], which requires a choice in the context of increasing risk, than those with sham stimulation or unilateral DLPFC stimulation (anodal electrode over either the right or the left DLPFC with the cathodal electrode over the contralateral supraorbital region) [19].

Mengarelli et al. [46] performed an experiment relevant to choice modulation using tDCS. The authors showed that cathodal tDCS over the left DLPFC reduced choiceinduced preference change when compared to sham stimulation while performing the Lieberman et al. [41]'s modified version of Brehm's free-choice paradigm. In a study on delay-discounting choices using tDCS [30], anodal left/cathodal right DLPFC tDCS increased smaller immediate gains rather than larger-delayed options compared to sham stimulation. A tDCS study on moral judgment [37] applied anodal, cathodal, and sham stimulation to the left DLPFC for the evaluation of moral personal dilemmas (Greene et al. [27]). As a result, subjects receiving anodal stimulation applied to the left DLPFC decreased individual appropriateness ratings and shifted toward non-utilitarian actions when compared to cathodal tDCS and sham stimulation. These studies show that tDCS can modulate the tendency of choice response in free-choice paradigms, delay discounting choices, and moral dilemmas, depending on the stimulated region of the DLPFC.

In a sunk-cost effect study using tDCS [4], anodal, cathodal, or sham stimulation was applied over the right DLPFC with a reference over CZ according to groups. Anodal stimulation significantly increased a sunk-cost effect, but cathodal or sham stimulation did not change it. Also, tDCS did not influence choices when there were no investments. The results indicate that the right DLPFC is involved with the sunk-cost effect. In an exploration (trying something new)-exploitation (sticking with a proven strategy) trade-offs study using tDCS [61], separated groups received anodal, cathodal, or sham tDCS over the right frontopolar cortex (FPC). Cathodal stimulation increased choices of the highest rewards, but anodal stimulation induced choices affected less by anticipated rewards and more by recent negative reward prediction errors, indicating that the right FPC is involved in controlling both exploration and exploitation. Ouellet et al. [42] studied decisionmaking and cognitive impulse control using tDCS. Anodal tDCS over orbitofrontal cortex (OFC) regardless of laterality increased advantageous decision-making and cognitive impulse control, compared to sham stimulation, indicating that controlling OFC by tDCS helps regulate impulsive behavior in psychiatric populations.

Regarding maladaptive decision-making as represented by the "gambler's fallacy," [81], anodal tDCS to the left lateral prefrontal cortex (LPFC) increased use of the gambler's fallacy strategy. This indicates that the left LPFC contributes to subprime decisions regarding random events by carrying out decisions based on a false world model (outcome dependency). Hecht et al. [29] performed a study regarding how decisions are made in a probabilistic-guessing task, which used tDCS to deliver stimulation to the DLPFC of one hemisphere while concurrently inhibiting the DLPFC of the opposite for each hemisphere of the participant's brain. Participants were randomly assigned to the right anodal/left cathodal group, left anodal/right cathodal group, or control group/ no stimulation. Although there was no difference in strategy between the three groups, participants in the left anodal/right cathodal group decreased RT in choosing the most frequent alternative. The results may reflect that the left hemisphere plays an important role in probabilistic learning and reasoning. 
Woods et al. [79] used both fMRI and tDCS to identify areas hypothesized to be associated with perception of space and time, and decision-making using animated video clips of billiard balls. Following the fMRI, tDCS was used to validate the hypothesized neural correlates found from the fMRI. Different tDCS manipulations during three different sessions were performed on different areas of the brain: frontal, parietal, or sham stimulations. Parietal stimulation affected perception of spatial causality, while frontal stimulation affected perception of both spatial and temporal causality, indicating that the parietal lobe is related to causal perception of space and the frontal lobe is related to more general functions such as decision-making. In addition, in order to investigate what role the left posterior lateral prefrontal cortex (pLPFC) played in dual-task performance, Filmer et al. [22] used tDCS during three testing sessions on different days while using different tDCS stimulations to the left pLPFC during each session: anodal, cathodal, or sham. Behavioral tasks included single and multi-tasking trials where participants had to respond to a tone, an image, or both. RT for the multitask session was significantly reduced by the cathodal stimulation to the left pLPFC. This finding supports the theory that the left pLPFC is a crucial location for multitasking in humans.

A recent study explored how anodal tDCS on the right DLPFC affects model-based reinforcement learning ${ }^{2}$ vs. model-free learning techniques ${ }^{3}$ [70]. Smittenaar et al. [70] performed a within-subject double-blind study during two separate sessions in which participants were given either active or sham stimulation during a 2-alternative forcedchoice task, followed by a choice of one of two of the second stage stimuli, in which one stimuli was more strongly associated with the originally selected stimuli than the other. Results showed that active tDCS does not significantly affect model-based or model-free control during a behavioral task.

For addiction studies using tDCS modulation, cigarette consumption was measured for two five-day tDCS applications (active or sham). In smokers, active tDCS (right anodal/left cathodal tDCS to the DLPFC) significantly decreased the number of cigarettes smoked compared to sham stimulation and the effects were maintained for 4 days [17]. Boggio et al. [6] applied tDCS to the DLPFC (left anodal/right cathodal tDCS, right anodal/left cathodal tDCS, or sham tDCS) to chronic marijuana users in their study. During the sham stimulation, they showed less risky decision-making more frequently than young healthy subjects had shown in their previous study [18]. Also, young healthy subjects receiving right anodal/left cathodal DLPFC tDCS showed less risky tendencies [18]; both left anodal/right cathodal and right anodal/left cathodal tDCS to DLPFC showed riskier tendencies in marijuana users. However, in marijuana users, right anodal/ left cathodal tDCS of DLPFC decreased marijuana cravings significantly. In a study to compare cocaine users with non-abusers using tDCS [26], the subjects performed the BART and the Game of Dice Task (GDT) [7] immediately before and after each tDCS stimulation (a left anodal/right cathodal stimulation, a right anodal/left cathodal stimulation, and a sham stimulation at least 48-h intervals). For the BART, both cocaine users and non-abusers decreased risky behavior after both active tDCS. However, in the GDT, cocaine users increased their "safe" behavior after right DLPFC anodal stimulation and increased risk-taking behavior after left DLPFC anodal stimulation; however, control subjects increased safe behavior by only right DLPFC anodal stimulation. Pripfl et al. [60] investigated how anodal right/cathodal left DLPFC tDCS or anodal left/cathodal right DLPFC tDCS affect risk taking of smokers and nonsmokers by using the Columbia Card 
Task (CCT) [21] to assess risky decision-making which uses "affect-charged" (Hot CCT) vs. deliberative (Cold CCT). In both the smoking and nonsmoking groups, risk taking was decreased in the "cold" task after the anodal left tDCS, whereas risk-taking was decreased in smokers but was increased in non-smokers in the "hot" task after anodal right tDCS. These results are important because they show that with an increased ability to control impulsivity, smokers made more cautious decisions, whereas hindering riskaversion brain structures produced the opposite effect in nonsmokers. Also, in overnight abstinent smokers, anode tDCS to the left DLPFC and cathode tDCS to the right supra-orbital area significantly decreased negative affect, which positively correlated with the level of nicotine dependence but did not affect cigarette cravings and performance (RT and hit rate) on a visual attentional task [80]. Addiction modulation studies using tDCS suggest that tDCS can be effective tools for treating addictive behaviors in psychiatric populations.

In an appetite study using tDCS [23], anode left/cathode right tDCS of the DLPFC did not increase cravings, but sham stimulation did increase cravings, indicating that anode left/cathode right can suppress food cravings. In a study for women with frequent food cravings, anodal right/cathodal left tDCS decreased cravings for sweet foods, but not savory foods [35]. The study used temporal-discounting tasks to investigate impulsive-choice behavior of participants, showing that more reflective participants were more liable to tDCS effects inhibiting food cravings than more impulsive participants. However, there were no differences between real tDCS and sham tDCS in temporal-discounting tasks and actual food consumption. These studies indicate that food cravings in obesity populations may be controlled by tDCS.

In a perceptual decision-making study using tDCS [34], the brain region stimulated by tDCS was the primary motor cortex (PMC). Anodal tDCS over the PMC increased responses using the contralateral hand, whereas cathodal tDCS over the PMC increased responses using the ipsilateral hand. In all tDCS conditions, RTs decreased when response shifted toward the left hand and increased when response shifted away from the left hand. The results indicate that $\mathrm{tDCS}$ to the PMC can modulate motor responses and hand choice.

In summary, tDCS influences and modulates risk-taking behaviors $[5,12,18,19,47$, 82, 83], choice modulation [46], delayed discounting [30], maladaptive decisionmaking [81], probabilistic guessing [29], moral judgment [37], sunk-cost effect [4], exploration-exploitation trade-offs [61], decision-making and cognitive impulse control [42], perception of space and time [79], dual-task performance [22], model-based learning [70], addiction [6, 17, 26, 60, 80], food craving [23, 35], and perceptual decision-making [34].

\section{Conclusions and future research direction}

Recently, it has increasingly been reported that rTMS and tDCS can be applied to neuromodulation of various cognition and emotion functions. We reviewed emotion regulation and decision-making studies using rTMS and tDCS. Both rTMS and tDCS improve emotion regulation and decision-making abilities by modulating top-down regulation to the stimuli in experimental studies (Fig. 1). For rTMS, HF rTMS increases cortical excitability $[2,55]$, whereas LF rTMS inhibits cortical excitability [11]. The two stimulations induce neuronal plasticity [14, 40, 45, 74, 85, 86]. For tDCS, anodal stimulation increases the neuronal excitability and cathodal stimulation decreases the 
neuronal excitability [50,51]. Although tDCS's electrical fields tend to be more diffused and non-focal compared to rTMS [66], the two non-invasive tools are similar in improving or inhibiting the cognitive and emotional abilities. As mentioned above, emotion regulation and decision-making influence human behavior by top-down or bottom-up processing in the brain. rTMS and tDCS can modulate responses in behavioral tasks by influencing neuronal activation in the brain.

We reviewed the applications of rTMS and tDCS in emotion regulation and decisionmaking. Of rTMS and tDCS, tDCS takes advantages of emotion regulation and decisionmaking studies in perspective of simplicity of use and low expense. So far, tDCS has been extensively applied to decision-making tasks including moral judgment, risk-taking behaviors, choice modulation, delayed discounting, maladaptive decision-making, probabilistic guessing, perception of space and time, dual-task performance, model-based learning, addiction, food craving, sunk-cost effect, exploration-exploitation trade-offs, decisionmaking and cognitive impulse control, and perceptual decision-making. Comparatively, rTMS has been applied to delay discounting, food choice, moral judgment, visuospatial attention, perception, object identification, spatial working memory, function and manipulation tool knowledge, visuomotor task, and blameworthiness and punishment decisions. Thus far, tDCS studies for emotion regulation are more diverse than rTMS studies, such as arousal during emotion regulation, regulation of negative emotions in social exclusion, mathematics anxiety, emotional reactions to pain stimuli, negative affect for negative pictures, negative affect for negative stimuli, and momentary ruminative self-referent thoughts. On the other hand, rTMS has been applied to attentional aspects of emotion regulation, affective processing of emotional stimuli, autonomic reactions to affective pictures, and cerebellar stimulation. As such, tDCS has been used more extensively in a large variety of studies compared to rTMS, as shown in this review.

Reflecting on tDCS and rTMS studies in normal populations, more tDCS studies for patients with emotional and cognitive dysfunctions will be needed in the future. Although tDCS has been applied to the treatment of some psychiatric illnesses [84], there are few tDCS experiments that are applied either to clinical studies involving emotion dysregulation and abnormal decision-making such as suicidal ideations and attempts, or to severe problems in human relations and social adaption. As opposed to rTMS's application to clinical patients, tDCS has not been used extensively with clinical populations. Considering the potential effects of tDCS, extensive broader application of tDCS to emotion dysregulation and abnormal decision-making in psychiatric patients is essential in the future. The possibility of tDCS relevance is strong in psychiatric diseases. Both rTMS and tDCS could provide many benefits for treatments with addiction and other self-control problems. In this review, we see that both rTMS and tDCS have many implications to benefit those who have emotion regulation deficiencies, and future studies should further investigate this.

\section{Endnotes}

${ }^{1}$ Wealth effect means to be more conservative when expecting to get positive experiment benefits [24].

${ }^{2}$ learning based on inferences of the physical environment taken from observed data used to make future predictions.

${ }^{3}$ habitual responding which happens simply by saving information about outcomes and rewards from past encounters with the environment. 


\begin{abstract}
Abbreviations
rTMS, repetitive transcranial magnetic stimulation; tDCS, transcranial direct current stimulation; HF, High frequency; LF, Low frequency; PET, positron emission tomograph; DLPFC, dorsolateral prefrontal cortex; dACC, dorsal anterior cingulate cortex; TPJ, temporal parietal junction; SCR, skin conductance responses; rVLPFC, right ventrolateral prefrontal cortex; RT, reaction time; MPFC, medial prefrontal cortex; CTBS, continuous theta burst stimulation; AG, angular gyrus; PPC, posterior parietal cortex; ATL, anterior temporal lobe; IPL, inferior parietal lobule; BART, Balloon Analog Risk Task; FPC, frontopolar cortex; OFC, orbitofrontal cortex; LPFC, lateral prefrontal cortex; pLPFC, posterior lateral prefrontal cortex; CCT, Columbia Card Task; PMC, primary motor cortex
\end{abstract}

\title{
Acknowledgements
}

We appreciated Norah C. Hass for her comments and discussion on this paper.

\section{Funding}

This study was supported by the National Cancer Institute of the National Institutes of Health under Award Number R21CA184834 (PI: SLL). The content is solely the responsibility of the authors and does not necessarily represent the official views of the National Institutes of Health.

\section{Availability of data and materials}

Not applicable (All data came from previous studies listed in the references).

\section{Authors' contributions}

KMC and SLL conceived of the purpose for the review and its direction. KMC contributed to the development and organization of the manuscript. KMC wrote the first draft of the manuscript. SLL and DTS helped to revise the manuscript. All authors read and approved the final manuscript.

\section{Authors' information}

KMC is a postdoctoral researcher, DTS is a doctoral student, and SLL is an assistant professor in the Department of Psychology, University of Missouri-Kansas City.

\section{Competing interests}

The authors declare that they have no competing interests.

\section{Consent for publication}

Not applicable.

\section{Ethics approval and consent to participate}

Not applicable.

Received: 24 March 2016 Accepted: 2 June 2016

Published online: 10 June 2016

\section{References}

1. Alonzo A, Brassil J, Taylor JL, Martin D, Loo CK. Daily transcranial direct current stimulation (tDCS) leads to greater increases in cortical excitability than second daily transcranial direct current stimulation. Brain Stimul. 2012;5(3): 208-13. doi:10.1016/j.brs.2011.04.006.

2. Berardelli A, Inghilleri M, Rothwell JC, Romeo S, Currà A, Gilio F, et al. Facilitation of muscle evoked responses after repetitive cortical stimulation in man. Exp Brain Res. 1998;122:79-84.

3. Berger C, Domes G, Balschat J, Thome J, Höppner J. Effects of prefrontal rTMS on autonomic reactions to affective pictures. J Neural Transm. 2015. doi:10.1007/s00702-015-1491-4.

4. Bogdanov M, Ruff CC, Schwabe L. Transcranial stimulation over the dorsolateral prefrontal cortex increases the impact of past expenses on decision-making. Cereb Cortex. 2015. doi:10.1093/cercor/bhv298.

5. Boggio PS, Campanhã C, Valasek CA, Fecteau S, Pascual-Leone A, Fregni F. Modulation of decision-making in a gambling task in older adults with transcranial direct current stimulation. Eur J Neurosci. 2010a;31:593-7. doi:10.1111/j.1460-9568.2010.07080.x.

6. Boggio PS, Zaghi S, Villani AB, Fecteau S, Pascual-Leone A, Fregni F. Modulation of risk-taking in marijuana users by transcranial direct current stimulation (tDCS) of the dorsolateral prefrontal cortex (DLPFC). Drug Alcohol Depend. 2010b;112(3):220-5. doi:10.1016/j.drugalcdep.2010.06.019.

7. Brand M, Fujiwara E, Borsutzky S, Kalbe E, Kessler J, Markowitsch HJ. Decision-making deficits of Korsakoff patients in a new gambling task with explicit rules-associations with executive functions. Neuropsychology. 2005;19:267-77. doi:10.1037/0894-4105.19.3.267.

8. Brunoni AR, Vanderhasselt MA, Boggio PS, Fregni F, Dantas EM, Mill JG, et al. Polarity-and valence-dependent effects of prefrontal transcranial direct current stimulation on heart rate variability and salivary cortisol. Psychoneuroendocrinology. 2013;38:58-66.

9. Buckholtz JW, Martin JW, Treadway MT, Jan K, Zald DH, Jones O, et al. From blame to punishment: disrupting prefrontal cortex activity reveals norm enforcement mechanisms. Neuron. 2015;87(6):1369-80. doi:10.1016/.neuron.2015.08.023.

10. Camus M, Halelamien N, Plassmann H, Shimojo S, O'Doherty J, Camerer C, et al. Repetitive transcranial magnetic stimulation over the right dorsolateral prefrontal cortex decreases valuations during food choices. Eur J Neurosci. 2009;30(10):1980-8. doi:10.1111/j.1460-9568.2009.06991.x.

11. Chen R, Classen J, Gerloff C, Celnik P, Wassermann EM, Hallett M, et al. Depression of motor cortex excitability by low-frequency transcranial magnetic stimulation. Neurology. 1997;48:1398-403. 
12. Cheng GL, Lee TM. Altering risky decision-making: Influence of impulsivity on the neuromodulation of prefrontal cortex. Soc Neurosci. 2015. doi:10.1080/17470919.2015.1085895.

13. Cho SS, Koshimori Y, Aminian K, Obeso I, Rusjan P, Lang AE, et al. Investing in the future: stimulation of the medial prefrontal cortex reduces discounting of delayed rewards. Neuropsychopharmacology. 2015;40:546-53. doi:10.1038/npp.2014.211.

14. Choi KM, Jang KM, Jang Kl, Um YH, Kim MS, Kim DW, et al. The effects of 3 weeks of rTMS treatment on P200 amplitude in patients with depression. Neurosci Lett. 2014;577:22-7.

15. De Raedt R, Leyman L, Baeken C, Van Schuerbeek P, Luypaert R, Vanderhasselt MA, et al. Neurocognitive effects of HF-rTMS over the dorsolateral prefrontal cortex on the attentional processing of emotional information in healthy women: an event-related fMRI study. Biol Psychol. 2010;85:487-95. doi:10.1016/j.biopsycho.2010.09.015.

16. Ernst M, Paulus MP. Neurobiology of decision making: a selective review from a neurocognitive and clinical perspective. Biol Psychiatry. 2005;58:597-604

17. Fecteau S, Agosta S, Hone-Blanchet A, Fregni F, Boggio P, Ciraulo D, et al. Modulation of smoking and decisionmaking behaviors with transcranial direct current stimulation in tobacco smokers: a preliminary study. Drug Alcohol Depend. 2014;140:78-84. doi:10.1016/j.drugalcdep.2014.03.036.

18. Fecteau S, Knoch D, Fregni F, Sultani N, Boggio P, Pascual-Leone A. Diminishing risk-taking behavior by modulating activity in the prefrontal cortex: a direct current stimulation study. J Neurosci. 2007a;27:12500-5.

19. Fecteau S, Pascual-Leone A, Zald DH, Liguori P, Théoret H, Boggio PS, et al. Activation of prefrontal cortex by transcranial direct current stimulation reduces appetite for risk during ambiguous decision making. J Neurosci. 2007b;27:6212-8.

20. Feeser M, Prehn K, Kazzer P, Mungee A, Bajbouj M. Transcranial direct current stimulation enhances cognitive control during emotion regulation. Brain Stimul. 2014;7:105-12. doi:10.1016/j.brs.2013.08.006.

21. Figner B, Weber EU, Mackinlay RJ, Wilkening F. Affective and deliberative processes in risky choice: age differences in Risk taking in the Columbia Card Task. J Exp Psychol Learn Mem Cogn. 2009:35:709-30.

22. Filmer HL, Mattingley JB, Dux PE. Improved multitasking following prefrontal tDCS. Cortex. 2013;49:2845-52. doi:10.1016/j.cortex.2013.08.015.

23. Fregni F, Orsati F, Pedrosa W, Fecteau S, Tome FA, Nitsche MA, et al. Transcranial direct current stimulation of the prefrontal cortex modulates the desire for specific foods. Appetite. 2008:51:34-41. doi:10.1016/j.appet.2007.09.016.

24. Gneezy U, Potters J. An experiment on risk taking and evaluation periods. Q J Econ. 1997;1 12:631-45.

25. Gongora M, Bittencourt J, Teixeira S, Basile LF, Pompeu F, Droguett EL, et al. Low-frequency rTMS over the parieto-frontal network during a sensorimotor task: The role of absolute beta power in the sensorimotor integration. Neurosci Lett. 2016;611:1-5. doi:10.1016/j.neulet.2015.11.025.

26. Gorini A, Lucchiari C, Russell-Edu W, Pravettoni G. Modulation of risky choices in recently abstinent dependent cocaine users: a transcranial direct-current stimulation study. Front Hum Neurosci. 2014;8:661. doi:10.3389/fnhum.2014.00661.

27. Greene JD, Nystrom LE, Engell AD, Darley JM, Cohen JD. The neural bases of cognitive conflict and control in moral judgment. Neuron. 2004;44:389-400.

28. Greene JD, Sommerville RB, Nystrom LE, Darley JM, Cohen JD. An fMRI investigation of emotional engagement in moral judgment. Science. 2001;293:2105-8.

29. Hecht $D$, Walsh $V$, Lavidor M. Transcranial direct current stimulation facilitates decision making in a probabilistic guessing task. J Neurosci. 2010;30:4241-5. doi:10.1523/JNEUROSCI.2924-09.2010.

30. Hecht $\mathrm{D}$, Walsh V, Lavidor M. Bi-frontal direct current stimulation affects delay discounting choices. Cogn Neurosci. 2013:4:7-11. doi:10.1080/17588928.2011.638139

31. Herrington JD, Mohanty A, Koven NS, Fisher JE, Stewart JL, Banich MT, et al. Emotion-modulated performance and activity in left dorsolateral prefrontal cortex. Emotion. 2005;5:200-7.

32. Higgins ES, George MS. Brain stimulation therapies for clinicians. Washington, DC/London, England: American Psychiatric Publishing, Inc; 2009.

33. Ishibashi R, Lambon Ralph MA, Saito S, Pobric G. Different roles of lateral anterior temporal lobe and inferior parietal lobule in coding function and manipulation tool knowledge: evidence from an rTMS study. Neuropsychologia. 2011;49:1128-35. doi:10.1016/j.neuropsychologia.2011.01.004.

34. Javadi AH, Beyko A, Walsh V, Kanai R. Transcranial Direct Current Stimulation of the Motor Cortex Biases Action Choice in a Perceptual Decision Task. J Cogn Neurosci. 2015;27(11):2174-85. doi:10.1162/jocn_a_00848.

35. Kekic M, McClelland, Campbell I, Nestler S, Rubia K, David AS, et al. The effects of prefrontal cortex transcranial direct current stimulation (tDCS) on food craving and temporal discounting in women with frequent food cravings. Appetite. 2014;78:55-62.

36. Koch G, Oliveri M, Torriero S, Carlesimo GA, Turriziani P, Caltagirone C. rTMS evidence of different delay and decision processes in a fronto-parietal neuronal network activated during spatial working memory. Neuroimage. 2005;24(1):34-9.

37. Kuehne $M$, Heimrath $\mathrm{K}$, Heinze $\mathrm{HJ}$, Zaehle T. Transcranial direct current stimulation of the left dorsolateral prefrontal cortex shifts preference of moral judgments. PLoS One. 2015;10(5):e0127061. doi:10.1371/journal.pone.0127061.

38. Lang N, Siebner HR, Ward NS, Lee L, Nitsche MA, Paulus W, et al. How does transcranial DC stimulation of the primary motor cortex alter regional neuronal activity in the human brain? Eur J Neurosci. 2005;22:495-504.

39. Lejuez CW, Read JP, Kahler CW, Richards JB, Ramsey SE, Stuart GL, et al. Evaluation of a behavioral measure of risk taking: the Balloon Analogue Risk Task (BART). J Exp Psychol Appl. 2002; 8:75-84.

40. Lenz M, Galanis C, Müller-Dahlhaus F, Opitz A, Wierenga CJ, Szabó G, et al. Repetitive magnetic stimulation induces plasticity of inhibitory synapses. Nat Commun. 2016;7:10020. doi:10.1038/ncomms10020.

41. Lieberman MD, Ochsner KN, Gilbert DT, Schacter DL. Do amnesic exhibit cognitive dissonance reduction? The role of explicit memory and attention in attitude change. Psychol Sci. 2001;12:135-40.

42. Ouellet J, McGirr A, Van den Eynde F, Jollant F, Lepage M, Berlim MT. Enhancing decision-making and cognitive impulse control with transcranial direct current stimulation (tDCS) applied over the orbitofrontal cortex (OFC): A randomized and sham-controlled exploratory study. J Psychiatr Res. 2015;69:27-34. doi:10.1016/j.jpsychires.2015.07.018.

43. Pessoa L. On the relationship between emotion and cognition. Nat Rev Neurosci. 2008;9:148-58

44. Luo J, Yu R. Follow the heart or the head? The interactive influence model of emotion and cognition. Front Psychol. 2015;6:573. doi:10.3389/fpsyg.2015.00573. 
45. Ma J, Zhang Z, Kang L, Geng D, Wang Y, Wang M. Repetitive transcranial magnetic stimulation (rTMS) influences spatial cognition and modulates hippocampal structural synaptic plasticity in aging mice. Exp Gerontol. 2014;58: 256-68. doi:10.1016/j.exger.2014.08.011.

46. Mengarelli F, Spoglianti S, Avenanti A, di Pellegrino G. Cathodal tDCS over the left prefrontal cortex diminishes choice-induced preference change. Cereb Cortex. 2015;25:1219-27. doi:10.1093/cercor/bht314.

47. Minati L, Campanhã C, Critchley HD, Boggio PS. Effects of transcranial direct-current stimulation (tDCS) of the dorsolateral prefrontal cortex (DLPFC) during a mixed-gambling risky decision-making task. Cogn Neurosci. 2012;3:80-8. doi:10.1080/17588928.2011.628382.

48. Mitchell DG. The nexus between decision making and emotion regulation: a review of convergent neurocognitive substrates. Behav Brain Res. 2011;217:215-31.

49. Nitsche MA, Cohen LG, Wassermann EM, Priori A, Lang N, Antal A, et al. Transcranial direct current stimulation: State of the art 2008. Brain Stimul. 2008;1:206-23. doi:10.1016/j.brs.2008.06.004.

50. Nitsche MA, Paulus W. Sustained excitability elevations induced by transcranial DC motor cortex stimulation in humans. Neurology. 2001;57:1899-901.

51. Nitsche MA, Paulus W. Excitability changes induced in the human motor cortex by weak transcranial direct current stimulation. J Physiol. 2000;527:633-9.

52. Ochsner KN, Ray RD, Cooper JC, Robertson ER, Chopra S, Gabrieli JD, et al. For better or for worse: neural systems supporting the cognitive down- and up-regulation of negative emotion. Neuroimage. 2004;23:483-99.

53. Ochsner KN. What is the role of control in emotion life. In: Gazzaniga MS, Mangun GR, editors. The Cognitive Neurosciences. 5th ed. Cambridge, MA: MIT Press; 2014

54. Pascual-Leone A, Davey NJ, Rothwell J, Wasserman EM, Puri BK. Handbook of transcranial magnetic stimulation. London, UK: Arnold; 2002.

55. Pascual-Leone A, Valls-Sole J, Wassermann EM, Hallett M. Responses to rapid-rate transcranial magnetic stimulation of the human motor cortex. Brain. 1994;117:847-58.

56. Peña-Gómez C, Vidal-Piñeiro D, Clemente IC, Pascual-Leone A, Bartrés-Faz D. Down-regulation of negative emotional processing by transcranial direct current stimulation: effects of personality characteristics. PLoS One. 2011;6:e22812. doi:10.1371/journal.pone.0022812.

57. Philiastides MG, Auksztulewicz R, Heekeren HR, Blankenburg F. Causal role of dorsolateral prefrontal cortex in human perceptual decision making. Curr Biol. 2011;21:980-3. doi:10.1016/j.cub.2011.04.034.

58. Posner MI. Orientation of attention. Q J Exp Psychol. 1980;32:3-25.

59. Pripfl J, Lamm C. Focused transcranial direct current stimulation (tDCS) over the dorsolateral prefrontal cortex modulates specific domains of self-regulation. Neurosci Res. 2015;91:41-7. doi:10.1016/j.neures.2014.09.007.

60. Pripfl J, Neumann R, Köhler U, Lamm C. Effects of transcranial direct current stimulation on risky decision making are mediated by 'hot' and 'cold' decisions, personality, and hemisphere. Eur J Neurosci. 2013;38:3778-85. doi:10.1111/ejn.12375.

61. Raja Beharelle A, Polanía R, Hare TA, Ruff CC. Transcranial Stimulation over Frontopolar Cortex Elucidates the Choice Attributes and Neural Mechanisms Used to Resolve Exploration-Exploitation Trade-Offs. J Neurosci. 2015; 35(43):14544-56. doi:10.1523/JNEUROSCI.2322-15.2015.

62. Rêgo GG, Lapenta OM, Marques LM, Costa TL, Leite J, Carvalho S, et al. Hemispheric dorsolateral prefrontal cortex lateralization in the regulation of empathy for pain. Neurosci Lett. 2015;594:12-6. doi:10.1016/j.neulet.2015.03.042.

63. Riva P, Romero Lauro LJ, DeWall CN, Chester DS, Bushman BJ. Reducing aggressive responses to social exclusion using transcranial direct current stimulation. Soc Cogn Affect Neurosci. 2015a;10(3):352-6. doi:10.1093/scan/nsu053

64. Riva P, Romero Lauro LJ, Vergallito A, DeWall CN, Bushman BJ. Electrified emotions: Modulatory effects of transcranial direct stimulation on negative emotional reactions to social exclusion. Soc Neurosci. 2015b;10:46-54 doi:10.1080/17470919.2014.946621.

65. Rizzo V, Siebner HR, Modugno N, Pesenti A, Münchau A, Gerschlager W, et al. Shaping the excitability of human motor cortex with premotor rTMS. J Physiol. 2004;554:483-95.

66. Russell MJ, Goodman T, Pierson R, Shepherd S, Wang Q, Groshong B, et al. Individual differences in transcranial electrical stimulation current density. J Biomed Res. 2013;27(6):495-508. doi:10.7555/JBR.27.20130074.

67. Sarkar A, Dowker A, Cohen Kadosh R. Cognitive enhancement or cognitive cost: trait-specific outcomes of brain stimulation in the case of mathematics anxiety. J Neurosci. 2014;34:16605-10. doi:10.1523/JNEUROSCI.3129-14.2014.

68. Schutter DJ, van Honk J. The cerebellum in emotion regulation: a repetitive transcranial magnetic stimulation study. Cerebellum. 2009;8:28-34. doi:10.1007/s12311-008-0056-6.

69. Sheffer CE, Mennemeier M, Landes RD, Bickel WK, Brackman S, Dornhoffer J, et al. Neuromodulation of delay discounting, the reflection effect, and cigarette consumption. J Subst Abuse Treat. 2013;45:206-14. doi:10.1016/j.jsat.2013.01.012.

70. Smittenaar P, Prichard G, FitzGerald TH, Diedrichsen J, Dolan RJ. Transcranial direct current stimulation of right dorsolateral prefrontal cortex does not affect model-based or model-free reinforcement learning in humans. PLoS One. 2014;9:e86850. doi:10.1371/journal.pone.0086850.

71. Studer B, Cen D, Walsh V. The angular gyrus and visuospatial attention in decision-making under risk. Neuroimage. 2014;103:75-80. doi:10.1016/j.neuroimage.2014.09.003.

72. Tassy S, Oullier O, Duclos Y, Coulon O, Mancini J, Deruelle C, et al. Disrupting the right prefrontal cortex alters moral judgement. Soc Cogn Affect Neurosci. 2012:282-8. doi:10.1093/scan/nsr008.

73. Tings T, Lang N, Tergau F, Paulus W, Sommer M. Orientation-specific fast rTMS maximizes corticospinal inhibition and facilitation. Exp Brain Res. 2005;164:323-33.

74. Trebbastoni A, Pichiorri F, D'Antonio F, Campanelli A, Onesti E, Ceccanti M, et al. Altered cortical synaptic plasticity in response to $5-\mathrm{Hz}$ repetitive transcranial magnetic stimulation as a new electrophysiological finding in amnestic mild cognitive impairment converting to Alzheimer's disease: results from a 4-year prospective cohort study. Front Aging Neurosci. 2016;7:253. doi:10.3389/fnagi.2015.00253.

75. Vanderhasselt MA, Baeken C, Hendricks M, De Raedt R. The effects of high frequency rTMS on negative attentional bias are influenced by baseline state anxiety. Neuropsychologia. 2011;49:1824-30. doi:10.1016/j.neuropsychologia. 2011.03.006. 
76. Vanderhasselt MA, Brunoni AR, Loeys T, Boggio PS, De Raedt R. Nosce te ipsum-Socrates revisited? Controlling momentary ruminative self-referent thoughts by neuromodulation of emotional working memory. Neuropsychologia. 2013;51:2581-9. doi:10.1016/j.neuropsychologia.2013.08.011.

77. Viggiano MP, Giovannelli F, Borgheresi A, Feurra M, Berardi N, Pizzorusso T, et al. Disruption of the prefrontal cortex function by rTMS produces a category-specific enhancement of the reaction times during visual object identification. Neuropsychologia. 2008;46:2725-31. doi:10.1016/j.neuropsychologia.2008.05.004.

78. Wolkenstein L, Zeiller M, Kanske P, Plewnia C. Induction of a depression-like negativity bias by cathodal transcranial direct current stimulation. Cortex. 2014;59:103-12. doi:10.1016/j.cortex.2014.07.011.

79. Woods AJ, Hamilton RH, Kranjec A, Minhaus P, Bikson M, Yu J, Chatterjee A. Space, time, and causality in the human brain. Neuroimage. 2014;92:285-97. doi:10.1016/j.neuroimage.2014.02.015.

80. Xu J, Fregni F, Brody AL, Rahman AS. Transcranial direct current stimulation reduces negative affect but not cigarette craving in overnight abstinent smokers. Front Psychiatry. 2013;4:112. doi:10.3389/fpsyt.2013.00112.

81. Xue G, Juan CH, Chang CF, Lu ZL, Dong Q. Lateral prefrontal cortex contributes to maladaptive decisions. Proc Natl Acad Sci U S A. 2012;109:4401-6. doi:10.1073/pnas.1111927109.

82. Ye H, Chen S, Huang D, Wang S, Jia Y, Luo J. Transcranial direct current stimulation over prefrontal cortex diminishes degree of risk aversion. Neurosci Lett. 2015a;598:18-22. doi: 10.1016/j.neulet.2015.04.050.

83. Ye H, Chen S, Huang D, Wang S, Luo J. Modulating activity in the prefrontal cortex changes decision-making for risky gains and losses: a transcranial direct current stimulation study. Behav Brain Res. 2015b;286:17-21. doi:10.1016/j.bbr.2015.02.037.

84. Yokoi Y, Sumiyoshi T. Application of transcranial direct current stimulation to psychiatric disorders: trends and perspectives. Neuropsychiatric Electrophysiology. 2015;1:10. doi:10.1186/s40810-015-0012-X.

85. Zhang N, Xing M, Wang Y, Tao H, Cheng Y. Repetitive transcranial magnetic stimulation enhances spatial learning and synaptic plasticity via the VEGF and BDNF-NMDAR pathways in a rat model of vascular dementia. Neuroscience. 2015;311:284-91. doi:10.1016/j.neuroscience.2015.10.038.

86. Ziemann U, Paulus W, Nitsche MA, Pascual-Leone A, Byblow WD, Berardelli A, et al. Consensus: Motor cortex plasticity protocols. Brain Stimul. 2008;1(3):164-82. doi:10.1016/j.brs.2008.06.006.

87. Zwanzger P, Steinberg C, Rehbein MA, Bröckelmann AK, Dobel C, Zavorotnyy M, et al. Inhibitory repetitive transcranial magnetic stimulation (rTMS) of the dorsolateral prefrontal cortex modulates early affective processing. Neuroimage. 2014;101:193-203. doi:10.1016/j.neuroimage.2014.07.003.

\section{Submit your next manuscript to BioMed Central and we will help you at every step:}

- We accept pre-submission inquiries

- Our selector tool helps you to find the most relevant journal

- We provide round the clock customer support

- Convenient online submission

- Thorough peer review

- Inclusion in PubMed and all major indexing services

- Maximum visibility for your research

Submit your manuscript at www.biomedcentral.com/submit 